\title{
Atitudes de Estudantes de Medicina diante do Comportamento Suicida e Fatores Associados
}

\section{Attitudes of Medical Students towards Suicidal Behavior and Associated Factors}

Emerson Arcoverde Nunes ${ }^{1}$ (D) Beatriz Bezerril de Oliveira ${ }^{\mathrm{I}}$ (D) Lucas Bezerril de Lima Galvão ${ }^{1}$

\section{PALAVRAS-CHAVE}

- Suicídio.

- Tentativa de Suicídio.

- Estudantes.

- Educação de Graduação em Medicina.

- Atitude.

Introdução: O objetivo deste estudo foi avaliar a autoconfiança e o conhecimento de estudantes de Medicina para que possam atuar no cuidado de paciente sob risco suicida. Método: Trata-se de estudo transversal quantitativo realizado com amostra de 310 estudantes de Medicina do câmpus da Universidade Federal do Rio Grande do Norte (UFRN), em Natal, no Brasil. Para coleta dos dados dos estudantes, aplicou-se o Questionário de Atitudes Frente ao Comportamento Suicida (QuACS) associado a um questionário sociodemográfico. Para análise dos dados, foram utilizados os testes de correlação de Mann-Whitney e Spearman. Resultados: Os estudantes mais próximos do final do curso e aqueles que já tinham experiência prática com o suicídio demonstraram menos sentimentos negativos, maior sensação de capacidade profissional e atitude menos condenatória com relação ao suicídio. Os alunos do início do curso demonstraram mais sentimentos negativos para com o suicídio. Não houve influência estatisticamente relevante de sexo, possuir amigo ou familiar que já tentou suicídio ou experiência prévia de pensamentos suicidas nos resultados obtidos. Conclusão: O estudo reforça a correlação da implementação de experiências práticas e atividades de capacitação dos alunos com redução de sentimentos negativos e aumento de percepção de capacidade profissional para lidar com o comportamento suicida. 


\section{KEYWORDS}

- Suicide.

- Suicide Attempted.

- Students.

- Schools Medical.

- Attitude.

Recebido em 19/1/20

Aceito em 20/8/20

\section{INTRODUÇÃO}

Derivada do latim, a palavra suicídio possui seus primeiros registros históricos no século XVII, na obra Religio Medici, de Sir Thomas Browne ${ }^{1,2}$. Ainda na Antiguidade, na cultura greco-romana, o suicídio constituía-se em uma transgressão estatal, e, mais tarde, com as religiões monoteístas, esse ato passou a ter relevância teológica, sendo estigmatizado como prática injusta e não digna. Foi somente no século XIX, por intermédio de autores como Claude-Étienne Bourdin e da escola psiquiátrica de Esquirol, que o suicídio tornou-se objeto de estudo da medicina, começando então a ser entendido como um fenômeno passível de interpretação patológica, sociológica e filosófica ${ }^{3,4}$.

Atualmente, o comportamento suicida possui índices de prevalência cada vez maiores e tem causado impactos importantes para a sociedade $\mathrm{e}$ para os serviços de saúde, reforçando a relevância de desenvolver estudos sobre o tema ${ }^{5}$. Segundo estimativas da Organização Mundial da Saúde (OMS), cerca de 800 mil pessoas morrem todos os anos em decorrência do suicídio. Entre os jovens de 15-29 anos, esse dado é ainda mais preocupante: considerando ambos os sexos, o suicídio se enquadra como a segunda maior causa de morte ${ }^{6}$. No mundo, a cada três segundos uma pessoa atenta contra a própria vida, e a cada 40 segundos uma pessoa comete, de fato, o suicídio. Estima-se que cada morte por essa causa tenha impacto na vida de pelo menos seis outras pessoas e que até o final de 2020 poderá ocorrer um incremento de $50 \%$ na incidência anual de mortes por suicídio ${ }^{7}$.

O suicídio é notadamente multicausal e tem como principais fatores de risco situações como tentativa pregressa de suicídio, baixo nível educacional ou econômico, uso abusivo de álcool ou outras drogas, diagnóstico de doença crônica ou incurável e ainda a existência de transtornos mentais. Este último fator está presente na maioria dos casos ${ }^{8}$.

A prevenção do suicídio requer a ação integrada de uma equipe multiprofissional capaz de identificar pacientes sob risco de suicídio e manejar adequadamente esses casos ${ }^{9,10}$. De acordo com Bertolote, Melo-Santos et al. ${ }^{11}$, as principais funções da equipe de saúde com relação ao comportamento suicida incluem identificar os fatores de risco, intervir para a remoção desses fatores e escolher a melhor medida terapêutica para proteger o paciente.

Estudos nessa área têm sugerido que entre $40 \%$ e $60 \%$ das pessoas que cometeram suicídio consultaram um médico no mês anterior ao ato,

\section{ABSTRACT}

Introduction: To evaluate the self-confidence and knowledge of medical students when caring for patients at risk for suicide. Methods: A quantitative cross-sectional study was performed with a sample of 310 medical students from the campus of Universidade Federal do Rio Grande do Norte (UFRN) in Natal, Brazil. Data was collected through the application of the Suicide Behavior Attitude Questionnaire (QuACS, Questionário de Atitudes Frente ao Comportamento Suicida) in association with a sociodemographic questionnaire. The Spearman and Mann-Whitney correlation tests were used to analyze the data. Results: Students closer to the end of the course and those who had practical experience with suicide showed less negative feelings, more sense of professional capacity and less condemnatory attitudes towards suicide. Students in the beginning of the course showed more negative feelings towards suicide. There was no statistically significant influence of gender, having a friend or family member who attempted suicide or past experience of suicidal thoughts on the results. Conclusion: The with less negative feelings and increased sense of professional capacity to deal with suicidal behavior. 
teórico, de modo que a vivência prática é, na maioria das vezes, insatisfatória ${ }^{17}$. Tendo em vista a importância da obtenção de dados sobre as estratégias de ensino atualmente adotadas pelos cursos, este estudo teve como objetivo avaliar a autoconfiança e o conhecimento de estudantes de Medicina para atuar no cuidado do paciente sob risco suicida.

\section{MÉTODOS}

Trata-se de um estudo transversal de caráter quantitativo realizado entre os anos de 2018 e 2019, no câmpus da Universidade Federal do Rio Grande do Norte (UFRN), na cidade de Natal (RN), no Brasil.

Os critérios de inclusão adotados foram condição de estudante do curso de Medicina a partir do quinto semestre letivo, idade igual ou superior a 18 anos e assinatura do Termo de Consentimento Livre e Esclarecido (TCLE). Optou-se por não abordar os alunos dos primeiros semestres pelo fato de que, nessa etapa do curso, os graduandos têm menor chance de entrar em contato com situações de suicídio em atividades do curso. No período da coleta de dados, a população elegível para o estudo era de 384 graduandos, divididos em 49 alunos do quinto período, 46 do sexto período, 52 do sétimo período, 49 do oitavo período, 50 do nono período, 49 do décimo período, 42 do $11^{\circ}$ período e $47 \mathrm{do} 12^{\circ}$ período. Foram excluídos 74 graduandos que não preencheram os instrumentos durante a coleta de dados. Desse modo, participaram do estudo 310 graduandos de Medicina.

A coleta de dados ocorreu durante o período de março a junho de 2019, no Hospital Universitário Onofre Lopes, tendo como locais de abordagem dos entrevistados os espaços de convivência e as salas de aulas dos estudantes do curso de Medicina. Os estudantes que atenderam aos critérios de inclusão foram convidados a responder a um questionário sociodemográfico e ao Questionário de Atitudes Frente ao Comportamento Suicida (QuACS) por meio de e-mails, mensagens em redes sociais e abordagem direta nos locais de aula. Os questionários foram adaptados para a internet por meio da ferramenta Google Forms. O tempo médio estimado para o preenchimento dos questionários foi de dez minutos.

O QuACS, construído e validado por Botega et al. ${ }^{18}$ em um estudo com profissionais de enfermagem, é composto de 21 afirmações, seguidas de uma escala visual de $10 \mathrm{~cm}$ ancorada, em suas extremidades, por "discordo totalmente" e "concordo plenamente". Para o presente estudo, a escala visual do QuACS foi adaptada para uma escala numérica graduada de 1 a 10, na qual os participantes assinalaram os pontos que melhor representavam as suas crenças. Cada item recebeu, então, uma pontuação de concordância de acordo com a marcação do participante. Se o entrevistado assinalou o ponto que corresponde a 8 na escala, por exemplo, considerou-se que havia concordância de $80 \%$ com a respectiva afirmação.

No estudo original, os itens foram reunidos em três fatores: 1 . sentimentos negativos diante do paciente; 2. percepção de capacidade profissional; e 3. direito ao suicídio. $O$ fator 1 inclui os itens 2, 5, 9, 13, 15, 17 e 19 do questionário, com um máximo de 70 pontos. Quanto maior a pontuação nesse fator, maior a presença de sentimentos negativos. $\mathrm{O}$ fator 2 inclui os itens $1,7,10$, e o item 12 com valor negativo, com um máximo de 40 pontos. Maiores pontuações nesse fator indicam maior percepção de capacidade profissional para lidar com o comportamento suicida. $\mathrm{O}$ fator 3 inclui o item 3 com valor negativo e os itens 4, 6, 16 e 18, com um máximo de 50 pontos. Uma maior pontuação nesse fator indica atitude menos "moralista".

Os itens $8,11,14,20$ e 21 não são somados, pois não possuem semelhança com os fatores construídos. Podem, portanto, ser analisados separadamente ou excluídos da análise da escala. Calculou-se o coeficiente alfa de Cronbach para cada fator, e os resultados obtidos foram, respectivamente, $0,7,0,6$ e $0,5^{18}$.

Para o presente estudo, foi acrescida ao questionário original uma seção com dados sociodemográficos incluindo idade, gênero, período da graduação e pesquisa de capacitações sobre o tema, atendimento de algum caso de suicídio ou parentesco com pessoas que cometeram suicídio.

Os dados obtidos pela aplicação dos questionários na ferramenta Google Forms foram automaticamente gerados no programa Microsoft Excel. Posteriormente, foram transportados da planilha para o software Statistical Package for the Social Sciences (SPSS) para Windows versão 22.0.

Para os dados que não tiveram distribuição normal, avaliados pelo teste Kolmogorov-Smirnov, utilizaram-se os testes não paramétricos de Mann-Whitney, Spearman e Kruskal-Wallis com comparação por pairwise para a análise dos dados. O nível de significância adotado foi de $\mathrm{p}<0,05$.

A pesquisa seguiu as diretrizes e normas da Resolução no 466/2012, do Ministério da Saúde, que regulamenta os processos de investigação envolvendo seres humanos. A pesquisa foi iniciada após aprovação pelo Comitê de Ética em Pesquisa da UFRN (Parecer de Aprovação no 3.084.901). A participação dos estudantes ocorreu somente mediante a concordância com TCLE. Garantiu-se o sigilo e o anonimato de todas as informações, e os entrevistados tiveram a liberdade de retirar seus consentimentos a qualquer momento sem qualquer penalidade.

\section{RESULTADOS}

Os dados sociodemográficos e acadêmicos dos participantes do estudo estão dispostos na Tabela 1. A idade dos entrevistados variou de 18 a 46 anos, com média de 23 anos. A maioria dos estudantes tinha entre 20 e 25 anos no momento da coleta de dados.

A maioria dos estudantes era do sexo masculino (53,9\%), já tinha atendido algum paciente sob risco de suicídio (71,6\%), não tinha feito nenhum curso de capacitação sobre o tema $(79,4 \%)$ e possuía algum amigo ou familiar que já tentou suicídio $(58,4 \%)$. No item que indagava sobre o grau de associação entre doenças mentais e suicídio, as respostas variaram entre $0 \%$ e $100 \%$, com média de $85 \%$. A maioria dos entrevistados $(78,3 \%)$ respondeu com porcentagens entre $75 \%$ e $100 \%$.

A Tabela 2 reúne as respostas dos estudantes em cada um dos itens do QuACS. Em todos os itens, foram obtidas as pontuações mínimas (0) e máximas (10). A afirmação com a menor média e maior concordância foi a questão 16 - "Quem tem Deus no coração, não vai tentar se matar" -, demonstrando uma atitude menos condenatória dos entrevistados. A afirmação 8 - "Geralmente, quem se mata tem alguma doença mental" - apresentou a maior média, o que está em concordância com a pergunta "Em sua opinião, entre as pessoas que cometeram suicídio, quantas você estima que sofriam de doença mental? (porcentagem)" da primeira seção do questionário.

A Tabela 3 reúne os resultados obtidos em cada fator do QuACS. Verifica-se que o fator 1 apresentou a menor pontuação máxima de acordo com seu valor de referência, indicando que os entrevistados possuíam menor percepção de sentimentos negativos relacionados ao paciente suicida. A menor média e a menor pontuação mínima foram obtidas no fator 2 , ressaltando uma baixa percepção de capacidade profissional para lidar com o suicídio. $\mathrm{O}$ fator 3 apresentou a maior média e a menor discordância, demonstrando uma atitude menos moralista dos entrevistados.

REVISTA BRASILEIRA DE EDUCAÇÃO MÉDICA

3 44(4): e131; 2020 


\begin{tabular}{|c|c|}
\hline \multicolumn{2}{|c|}{$\begin{array}{c}\text { Tabela 1 } \\
\text { Divisão por número e porcentagem das variáveis sociodemográficas } \\
\text { e acadêmicas dos } 310 \text { participantes do estudo, Natal/RN, } 2019\end{array}$} \\
\hline Variáveis & $\mathbf{N}^{\circ}, \%$ \\
\hline \multicolumn{2}{|l|}{ Sexo } \\
\hline Feminino & $143(46,1 \%)$ \\
\hline Masculino & $167(53,9 \%)$ \\
\hline \multicolumn{2}{|l|}{ Idade } \\
\hline$<20$ & $5(1,6 \%)$ \\
\hline $20-25$ & $223(71,9 \%)$ \\
\hline $25-30$ & $68(21,9 \%)$ \\
\hline$>30$ & $14(4,5 \%)$ \\
\hline \multicolumn{2}{|l|}{ Período do curso } \\
\hline 5 & $41(13,2 \%)$ \\
\hline 6 & $41(13,2 \%)$ \\
\hline 7 & $45(15,5 \%)$ \\
\hline 8 & $40(12,9 \%)$ \\
\hline 9 & $41(13,2 \%)$ \\
\hline 10 & $36(11,6 \%)$ \\
\hline 11 & $31(10 \%)$ \\
\hline 12 & $35(11,3 \%)$ \\
\hline
\end{tabular}

Já atendeu algum paciente sob risco de suicídio?

$\begin{array}{lc}\text { Sim } & 222(71,6 \%) \\ \text { Não } & 88(28,4 \%)\end{array}$

Já fez algum curso de capacitação sobre o suicídio?

$\begin{array}{lr}\text { Sim } & 64(20,6 \%) \\ \text { Não } & 246(79,4 \%)\end{array}$

Possui algum amigo/familiar que já tentou o suicídio?

$\begin{array}{ll}\text { Sim } & 181(58,4 \%) \\ \text { Não } & 129(41,6 \%)\end{array}$

Em sua opinião, entre as pessoas que cometeram suicídio, quantas você estima que sofriam de doença mental? (porcentagem)

$\begin{array}{cc}0 & 2(0,6 \%) \\ 01 \text { a } 25 & 8(2,5 \%) \\ 25 \text { a } 50 & 16(5,1 \%) \\ 51 \text { a } 75 & 41(13,2 \%) \\ 75 \text { a } 99 & 119(38,3 \% \\ 100 & 124(40 \%)\end{array}$

Fonte: Elaborada pelos autores.

\section{Tabela 2}

Intervalo de respostas, mediana, média e desvio padrão das

pontuações obtidas pelos participantes do estudo nos itens do

QuACS, Natal/RN, 2019

\begin{tabular}{|c|c|c|c|}
\hline Questões & $\begin{array}{l}\text { Intervalo de } \\
\text { respostas }\end{array}$ & Mediana & $\begin{array}{l}\text { Média } \\
\text { (DP) }\end{array}$ \\
\hline $\begin{array}{l}\text { Me sinto capaz de ajudar uma pessoa } \\
\text { que tentou se matar (Q1) }\end{array}$ & $1-10$ & 6 & $5,65(2,1)$ \\
\hline $\begin{array}{l}\text { Quem fica ameaçando, geralmente } \\
\text { não se mata }(\mathrm{Q} 2)\end{array}$ & $1-10$ & 1 & $1,86(1,79)$ \\
\hline $\begin{array}{l}\text { Apesar de tudo, penso que uma } \\
\text { pessoa tem o direito de se matar (Q3) }\end{array}$ & $1-10$ & 4 & $4,05(2,70)$ \\
\hline $\begin{array}{l}\text { Diante de um suicídio penso: se } \\
\text { alguém tivesse conversado, a pessoa } \\
\text { teria encontrado outro caminho (Q4) }\end{array}$ & $1-10$ & 8 & $7,34(1,99)$ \\
\hline $\begin{array}{l}\text { No fundo, prefiro não me envolver } \\
\text { muito com pacientes que tentaram o } \\
\text { suicídio (Q5) }\end{array}$ & $1-10$ & 3 & $3,69(2,55)$ \\
\hline $\begin{array}{l}\text { A vida é um dom de Deus, e só Ele } \\
\text { pode tirar (Q6) }\end{array}$ & $1-10$ & 4 & $4,41(3,19)$ \\
\hline $\begin{array}{l}\text { Me sinto capaz de perceber quando um } \\
\text { paciente tem risco de se matar (Q7) }\end{array}$ & $1-10$ & 6 & $5,75(2,15)$ \\
\hline $\begin{array}{l}\text { Geralmente, quem se mata tem } \\
\text { alguma doença mental (Q8) }\end{array}$ & $1-10$ & 8 & $8,07(2,07)$ \\
\hline $\begin{array}{l}\text { Tenho receio de perguntar sobre } \\
\text { ideias de suicídio, e acabar induzindo } \\
\text { o paciente a isso (Q9) }\end{array}$ & $1-10$ & 2 & $3,28(2,68)$ \\
\hline $\begin{array}{l}\text { Acho que tenho preparo profissional } \\
\text { para lidar com pacientes com risco }\end{array}$ & $1-10$ & 5 & $4,52(2,93)$ \\
\hline
\end{tabular}

de suicídio (Q10)

$\begin{array}{lccc}\begin{array}{l}\text { Acho que é preciso ser uma pessoa } \\ \text { corajosa para se matar (Q11) }\end{array} & 1-10 & 5 & 5,48(3,12) \\ \begin{array}{l}\text { Sinto-me inseguro(a) para cuidar de } \\ \text { pacientes com risco de suicídio (Q12) }\end{array} & 1-10 & 7 & 6,60(2,52)\end{array}$

Às vezes dá raiva, porque tanta gente
querendo viver... e aquele paciente
querendo morrer (Q13)

Se eu sugerir um encaminhamento ao psiquiatra para um paciente que falou em se matar, penso que isso será bem $1-10 \quad 8$

aceito pelo psiquiatra (Q14)

\begin{tabular}{|c|c|c|c|}
\hline $\begin{array}{l}\text { A gente se sente impotente diante de } \\
\text { uma pessoa que quer se matar (Q15) }\end{array}$ & $1-10$ & 7 & $6,24(2,57)$ \\
\hline $\begin{array}{l}\text { Quem tem Deus no coração, não vai } \\
\text { tentar se matar (Q16) }\end{array}$ & $1-10$ & 1 & $1,65(1,52)$ \\
\hline $\begin{array}{l}\text { No caso de pacientes que estejam } \\
\text { sofrendo muito devido a uma doença } \\
\text { física, acho mais aceitável a ideia de } \\
\text { suicídio (Q17) }\end{array}$ & $1-10$ & 4 & $4,20(2,78)$ \\
\hline $\begin{array}{l}\text { Quando uma pessoa fala de pôr fim } \\
\text { à vida, tento tirar aquilo da cabeça }\end{array}$ & $1-10$ & 7 & $7,15(2,29)$ \\
\hline
\end{tabular}
dela (Q18) 


\begin{tabular}{|c|c|c|c|}
\hline \multicolumn{4}{|c|}{ Continuação } \\
\hline Questões & $\begin{array}{l}\text { Intervalo de } \\
\text { respostas }\end{array}$ & Mediana & $\begin{array}{l}\text { Média } \\
\text { (DP) }\end{array}$ \\
\hline $\begin{array}{l}\text { Quem quer se matar mesmo, não } \\
\text { fica "tentando" se matar (Q19) }\end{array}$ & $1-10$ & 1 & $1,71(1,54)$ \\
\hline $\begin{array}{l}\text { Um paciente internado dificilmente } \\
\text { se mata sem que tenha um forte } \\
\text { motivo pra isso (Q20) }\end{array}$ & $1-10$ & 3 & $3,32(2,57)$ \\
\hline $\begin{array}{l}\text { Eu já passei por situações que me } \\
\text { fizeram pensar em suicídio (Q21) }\end{array}$ & $1-10$ & 3 & $4,45(3,50)$ \\
\hline
\end{tabular}

Fonte: Elaborada pelos autores.

\section{Tabela 3}

Intervalo de respostas, pontuação máxima, média, desvio padrão e

mediana dos resultados obtidos pelos participantes da pesquisa nos

fatores estudados pelo QuACS, Natal/RN, 2019

\begin{tabular}{lcccc}
\multicolumn{1}{c}{ Fatores } & $\begin{array}{c}\text { Intervalo de } \\
\text { respostas }\end{array}$ & $\begin{array}{c}\text { Pontuação } \\
\text { máxima }\end{array}$ & $\begin{array}{c}\text { Média } \\
(\text { DP) }\end{array}$ & Mediana \\
$\begin{array}{l}\text { Fator 1 - Sentimentos } \\
\text { negativos diante do }\end{array}$ & $7-49$ & 70 & $\begin{array}{c}22,91 \\
(8,20)\end{array}$ & 22 \\
$\begin{array}{l}\text { paciente suicida } \\
\text { Fator 2 - Percepção de }\end{array}$ & $3-39$ & 40 & 19,32 & \\
capacidade profissional & & & $(7,44)$ & 20 \\
$\begin{array}{l}\text { Fator 3 - Direito ao } \\
\text { suicídio }\end{array}$ & $9-48$ & 50 & $\begin{array}{c}26,50 \\
(6,78)\end{array}$ & 26 \\
\hline
\end{tabular}

Fonte: Elaborada pelos autores.
A Tabela 4 apresenta a relação entre cada um dos períodos letivos entrevistados e a pontuação média obtida no QuACS. É possível observar menos sentimentos negativos e maior percepção de capacidade profissional em relação ao paciente sob risco suicida na turma do $12^{\circ}$ período. Menores percepções de capacidade profissional são observadas no quinto e sexto períodos. A maior percepção de sentimentos negativos relacionada ao paciente suicida é observada na turma do quinto período, que ainda não teve contato com nenhuma disciplina relacionada à psiquiatria ou à saúde mental. A turma que apresentou a maior média no fator 3 - direito ao suicídio - foi a turma do décimo período.

A Tabela 5 apresenta as comparações entre as médias obtidas no QuACS, segundo as variáveis sociodemográficas e educacionais. Observase que entrevistados que já haviam atendido algum paciente sob risco de suicídio ou já tinham feito algum curso de capacitação sobre o tema obtiveram maiores pontuações nos fatores 1 e 2 , demonstrando que tais pessoas possuíam menos sentimentos negativos quanto ao paciente sob risco de suicídio e consideravam que tinham uma maior capacidade profissional para lidar com o tema.

No fator 3, a única variável que apresentou relevância estatística foi o atendimento prévio a algum paciente sob o risco de suicídio, demonstrando a importância da prática médica. Não houve diferença significativa entre sexo ou possuir familiares/amigos que já tentaram suicídio com relação à pontuação obtida nos fatores.

A aplicação do teste não paramétrico de Kruskal-Wallis na análise da pontuação obtida fatores em relação ao período dos entrevistados no momento da coleta de dados demonstrou que houve diferenças significativas nos fatores 1 e $2(p=0,00)$ em relação ao período dos entrevistados. Esse teste orientou a realização de comparações múltiplas por pairwise, no entanto comparações múltiplas não foram realizadas para o fator 3, pois o teste inteiro não apresentou diferenças significativas entre as amostras.

Comparação de resultados de média, desvio padrão (DP) e mediana em cada fator analisado no formulário QuACS, de acordo com os períodos (P) do curso de Medicina da UFRN, Natal/RN, 2019

\begin{tabular}{|c|c|c|c|c|c|c|c|}
\hline \multirow[t]{2}{*}{ Variável } & \multirow[t]{2}{*}{$\mathbf{N}$} & \multicolumn{2}{|c|}{ Fator 1} & \multicolumn{2}{|c|}{ Fator 2} & \multicolumn{2}{|c|}{ Fator 3} \\
\hline & & Média (DP) & Mediana & Média (DP) & Mediana & Média (DP) & Mediana \\
\hline P5 & 41 & $27,39(8,03)$ & 27 & $13,66(5,75)$ & 13 & $26,56(5,42)$ & 26 \\
\hline P6 & 41 & $25,34(7,55)$ & 23 & $13,12(6,64)$ & 12 & $24,83(6,96)$ & 25 \\
\hline P7 & 45 & $25,64(7,38)$ & 25 & $17,11(5,63)$ & 18 & $27,51(7,87)$ & 27 \\
\hline P8 & 40 & $22,13(7,68)$ & 20 & $20,05(6,66)$ & 21 & $26,90(7,15)$ & 25 \\
\hline P9 & 41 & $22,02(8,07)$ & 20 & $20,85(6,11)$ & 22 & $25,07(5,65)$ & 24 \\
\hline P10 & 36 & $21,11(7,62)$ & 21,5 & $23,31(6,04)$ & 23 & $28,50(6,96)$ & 28,5 \\
\hline P11 & 31 & $20,35(7,34)$ & 18 & $23,77(5,82)$ & 24 & $25,23(7,39)$ & 25 \\
\hline P12 & 35 & $17,34(7,93)$ & 16 & $25,37(6,43)$ & 24 & $27,40(6,15)$ & 28 \\
\hline
\end{tabular}

Fonte: Elaborada pelos autores. 


\begin{tabular}{|c|c|c|c|c|c|c|}
\hline Domparação & $\begin{array}{l}\text { esvio padrão } \\
\text { sociodem }\end{array}$ & $\begin{array}{l}\text { e p (p-va } \\
\text { e educac }\end{array}$ & $\begin{array}{l}\text { bela } 5 \\
\text { da fator anal } \\
\text { participantes }\end{array}$ & $\begin{array}{l}\text { questiona } \\
\text { iisa, Nata }\end{array}$ & $\begin{array}{l}\text { CS, de acord } \\
19\end{array}$ & ariáveis \\
\hline \multirow[t]{2}{*}{ Variável } & \multicolumn{2}{|c|}{ Fator 1} & \multicolumn{2}{|c|}{ Fator 2} & \multicolumn{2}{|c|}{ Fator 3} \\
\hline & Média (DP) & p-value & Média (DP) & p-value & Média (DP) & p-value \\
\hline Sexo & & 0,26 & & 0,02 & & 0,9 \\
\hline Feminino & $23,48(8,41)$ & & $18,34(6,82)$ & & $26,44(6,65)$ & \\
\hline Masculino & $22,42(8,01)$ & & $20,16(7,85)$ & & $26,56(6,90)$ & \\
\hline
\end{tabular}

Já atendeu algum paciente sob risco de suicídio?

0,00

$\begin{array}{ll}\text { Sim } & 22,00(8,43) \\ \text { Não } & 25,20(7,15)\end{array}$

Já fez algum curso de capacitação sobre o suicídio?

0,00

0,00

0,06

$\begin{array}{ll}\text { Sim } & 20,08(7,88) \\ \text { Não } & 23,65(8,14)\end{array}$

$23,22(7,02)$

$18,33(7,24)$
0,00

0,04

$21,41(6,86)$

$14,06(6,15)$

$26,99(6,72)$

$25,27(6,79)$

$27,95(6,27)$

$26,13(6,87)$

Possui algum amigo/familiar que já tentou o suicídio?

0,97

0,45

$19,94(7,06)$

$26,32(6,59)$

$18,44(7,88)$

$26,76(7,05)$

Fonte: Elaborada pelos autores.

Foram realizadas então comparações em pares no Fator 1, no qual houve diferenças significativas na comparação do décimo segundo período com os três períodos iniciais do estudo $(p=0,00)$, do décimo primeiro período com o quinto $(\mathrm{p}=0,00)$ e o sétimo períodos $(\mathrm{p}=0,01)$ e o décimo, o nono e o oitavo períodos também obtiveram menores pontuações no quesito "sentimentos negativos" do que o quinto período (respectivamente: $\mathrm{p}=0,00, \mathrm{p}=0,03$ e $\mathrm{p}=0,05$ ).

Todas as turmas do internato (nono, décimo, décimo primeiro e décimo segundo) obtiveram diferenças significativas quando comparados à turma que ainda não tinha tido nenhum contato com a psiquiatria no curso de Medicina. Além disso, a turma do décimo segundo período foi a que apresentou os melhores resultados na comparação com os demais períodos.

O Fator 2 também foi analisado por comparações em pares, as quais demonstraram diferenças significativas entre as turmas do décimo segundo, décimo primeiro, décimo, nono e oitavo períodos e as turmas do quinto e sexto períodos ( $\mathrm{p}=0,00$ para todas as comparações). Ademais, as turmas do décimo, décimo primeiro e décimo segundo períodos também apresentaram diferenças estatísticas quando comparadas ao sétimo período $(\mathrm{p}=0,00)$. As três turmas iniciais do estudo foram as que obtiveram a menor média no Fator 2, indicando menor sensação de capacidade para lidar com um paciente sob risco de suicídio.

\section{DISCUSSÃO}

Este estudo teve por objetivos avaliar o conhecimento e as atitudes dos estudantes de Medicina da UFRN acerca do suicídio e analisar quais eram as características sociodemográficas e educacionais que exerciam influência nesses aspectos.

Não houve diferença estatisticamente significativa entre sexo feminino ou masculino e os escores do QuACS, e, em cada uma das 21 afirmações do questionário, ocorreu a indicação da concordância e da discordância plena, demonstrando que as opiniões e atitudes relacionadas a cada uma das perguntas referentes ao suicídio e seus fatores eram variadas. Tal achado é consistente com estudos realizados entre profissionais de enfermagem ${ }^{19}$.

Segundo dados da OMS, o principal fator de risco identificável para o suicídio é a presença concomitante de transtornos mentais ${ }^{14}$. No presente estudo, os entrevistados também obtiveram altas taxas de associação (85\%). No entanto, é necessário salientar que dois dos entrevistados negaram qualquer associação entre essas variáveis.

Ao contrário do que se esperava, possuir algum amigo/familiar que já tentou o suicídio não se relacionou a alterações significativas em nenhum dos fatores, demonstrando que apenas o contato proveniente de experiências profissionais e capacitações adequadas foram capazes de minimizar preconceitos e aprimorar as habilidades no manejo desses pacientes. Tal assertiva é reforçada pelo fato de que entrevistados que assinalaram uma maior pontuação no item 21 - "Eu já passei por situações que me fizeram pensar em suicídio” -, demonstrando que já haviam passado por algum sofrimento psíquico que os levou a pensar em cometer suicídio, não se mostraram mais capacitados para lidar com pacientes que também experienciaram esse sofrimento.

É importante ressaltar que 47 (15\%) dos entrevistados obtiveram concordância máxima com o item da questão 21, afirmando que já passaram por situações que os levaram a pensar em cometer suicídio. Esse achado é importante porque indica a necessidade da constante avaliação da saúde mental dos estudantes de Medicina, visto que estudos apontam que a taxa de suicídio em médicos é de três a cinco vezes maior do que a da população geral ${ }^{20}$. Sugere-se então que sejam realizados mais estudos que

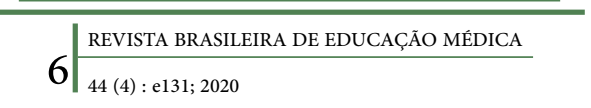


rastreiem a fundo o risco de suicídio nessa população e a implementação de intervenções de suporte para esses estudantes.

Verificou-se que os estudantes que estão no final do curso são menos propensos a apresentar sentimentos negativos com relação ao suicídio, se sentem mais capacitados ao lidarem com o problema e também possuem maior percepção de direitos acerca do suicídio, demonstrando que um maior nível educacional relacionado ao ambiente de prática dos dois últimos anos de estágio do curso de Medicina contribuem para a redução da estigmatização do paciente suicida e podem contribuir para uma assistência mais qualificada a esses pacientes.

Entrevistados que já haviam tido alguma experiência prática atendendo algum paciente sob risco de autoextermínio também apresentaram melhores pontuações nos três fatores analisados. Ter feito algum curso de capacitação também foi uma influência positiva nos fatores 1 e 2, demonstrando que o maior contato com essa temática influencia positivamente na percepção da capacidade profissional e torna menos comuns as atitudes condenatórias e negativas para com pacientes suicidas.

Alunos do quinto e sexto períodos apresentaram uma alta pontuação para o fator sentimentos negativos em relação ao paciente suicida. Essas atitudes estão mais associadas à falta de conhecimentos acerca do tema e podem influenciar negativamente na qualidade do serviço prestado. Cabe ressaltar que os alunos do quinto período ainda não experienciaram pelo curso de Medicina da UFRN qualquer disciplina relacionada à saúde mental, e os alunos do sexto período estavam, no período da coleta de dados, cursando a disciplina de psiquiatria.

Considerando a totalidade da amostra e a proporção dos valores máximos atribuídos para cada fator, os alunos do quinto ao $12^{\circ}$ período da UFRN apresentaram pontuações baixas no fator 1 (sentimentos negativos perante o paciente suicida), com pontuação máxima também reduzida (49). No entanto, os entrevistados também obtiveram baixas médias no fator 2 (percepção da capacidade profissional), demonstrando a necessidade da educação continuada sobre o tema, visto que eles não se sentiam suficientemente seguros para lidar com pacientes sob risco de suicídio.

Os alunos do quinto período obtiveram uma média de 13,66 no fator 2. Considerando que a essa altura do curso esses estudantes ainda estavam iniciando a primeira disciplina clínica e ainda não haviam tido nenhuma disciplina que envolvesse diretamente temas da psiquiatria, a média foi considerada consistente com estudos realizados com universitários brasileiros de cursos variados e sem capacitação sobre o tema, que obtiveram uma média de 15,5 nesse mesmo fator ${ }^{21}$.

Foi possível verificar um aumento progressivo desse fator de acordo com o passar dos períodos do curso. $\mathrm{O} 12^{\circ}$ período obteve um aumento de mais de $85 \%$ nesse fator quando comparado à turma do quinto período, demonstrando a positividade das ações em qualificação realizadas por meio de aulas expositivas e do contato com pacientes em atendimentos nas disciplinas clínicas, reforçando a necessidade de mais ações curriculares no âmbito da capacitação dos estudantes para o atendimento dessa população específica.

Um estudo realizado com alunos de Medicina de outra instituição brasileira $^{22}$ também encontrou resultados que apontavam para uma observação de que o grupo de estudantes já inseridos no ciclo cínico do curso apresentavam escores maiores quando comparados aos estudantes do ciclo pré-clínico, apontando para uma indicação de que discentes de períodos mais avançados exibiam atitudes mais positivas em relação ao suicídio quando comparados aos iniciantes no curso de Medicina. Embora esse estudo seja diferente do aqui realizado, os alunos não apresentaram diferenças significativas nos fatores 1 e 2 , e se constatou diferença significativa somente no escore final da escala $\mathrm{QuACS}^{22}$. Ademais, realizaram-se as análises em dois grupos (pré e pós-clínico), enquanto, no nosso estudo, as análises foram feitas comparando os períodos individualmente, o que pode ter proporcionado uma melhor avaliação quanto a possíveis intervenções a serem pensadas baseando-se nas nossas observações, com propostas de capacitações ou outras atividades didáticas referentes à prevenção de suicídio.

Vale ressaltar que a pontuação média de todos os estudantes avaliados neste estudo no fator $2(19,32)$ ainda foi menor que a pontuação média máxima possível para esse fator ( 40 pontos). Tal achado deve ser valorizado, visto que a insegurança profissional para lidar com o suicídio pode estar associada a uma insuficiência de conhecimento e, consequentemente, resultar em cuidados ineficazes e deficientes, prejudicando o usuário em risco para o suicídio ${ }^{23}$.

Destaca-se como limitação deste estudo a sua baixa abrangência, visto que ele foi conduzido em uma única universidade pública do Rio Grande do Norte, fazendo-se necessário expandir a amostra para outras universidades e outras regiões do país, de modo a aumentar a validade externa dos achados. Além disso, a adaptação do QuACS para o meio virtual, por causa da dificuldade de entrevistar os estudantes que estavam no internato de modo presencial, pode ter gerado respostas duplicadas, levando a vieses de informação. Tais vieses foram minimizados por meio do rastreio de respostas duplicadas no estudo.

Apesar dos três meses de coleta, apenas 310 dos 384 participantes elegíveis participaram do estudo (80,72\%), gerando, portanto, um viés de não resposta. Ademais, o QuACS, embora já validado, foi inicialmente utilizado em estudos com profissionais de enfermagem, enquanto neste estudo o público-alvo entrevistado foram graduandos do curso de Medicina.

\section{CONCLUSÃO}

O suicídio é um agravo de relevância crescente, e os pacientes com risco para esse comportamento são atendidos frequentemente por médicos recém-formados. Neste estudo, experiências pessoais envolvendo suicídio, como possuir algum amigo/familiar que já tentou suicídio ou ter passado de ideações suicidas, não mostraram correlação com os desfechos avaliados. A exposição em atividades de capacitação profissional, no entanto, mostrou correlação com a minimização de preconceitos e o aprimoramento das habilidades no manejo do suicídio. Apesar de esses fatores reforçarem a importância do emprego de estratégias efetivas para ensino do suicídio ainda durante a graduação, foi constatada baixa percepção de capacidade profissional nos alunos avaliados. Percebe-se, dessa maneira, a necessidade da realização de estudos que objetivem diagnosticar problemas e sugerir melhorias nas grades curriculares, para possibilitar a formação de médicos com habilidades compatíveis com a proeminência cada vez maior do comportamento suicida.

\section{REFERÊNCIAS}

1. Barraclough B, Shepherd D. A necessary neologism: the origin and uses of suicide. Suicide Life Threat Behav. 1994;24(2):113-26.

2. André W. Sobre o conceito de suicídio. Estação Literária. 2018;20:154-74.

3. Ribeiro DM. Suicídio: critérios científicos e legais de análise. Jus

7 REVISTA BRASILEIRA DE EDUCAÇÃo MÉDICA

7 44 (4) : e131; 2020 
Navigandi. 2004;9. Disponível em https://jus.com.br/artigos/5670.

4. Reis AH, Bezerra JMM, Reis PMS. O suicídio na visão do século XIX e na contemporaneidade - desafios aos paradigmas médico e psicológico. Revista Científica do UniRios. 2020.2:383-97.

5. Macchiaverni J. Elaboração de um instrumento para registro de atendimento psicológico a tentativas de suicídio. Santa Catarina: Universidade Federal de Santa Catarina; 2012.

6. World Health Organization. Suicide in the world: global health estimates. Geneva: WHO; 2019.

7. Conselho Federal de Medicina, Associação Brasileira de Psiquiatria. Suicídio: informando para prevenir. Brasília: Conselho Federal de Medicina, Associação Brasileira de Psiquiatria; 2014 [Avaliar ajuste].

8. Crump C, Sundquist K, Sundquist J, Winkleby MA. Sociodemographic, psychiatric and somatic risk factors for suicide: a Swedish national cohort study. Psychol Med. 2014;44(2):279-89.

9. Botega NJ, Werlang BSG, Cais CFS, Macedo MMK. Prevenção do comportamento suicida. Psico. 2006;37:213-20.

10. Müller $S$ de A, Pereira G, Zanon RB. Estratégias de prevenção e pósvenção do suicídio: estudo com profissionais de um Centro de Atenção Psicossocial. Rev. Psicol IMED. 2017;9(2):6-23.

11. Bertolote JM, Mello-Santos C, Botega NJ. Detecting suicide risk at psychiatric emergency services. Braz J Psychiatry. 2010;32(Suppl 2):S87-95.

12. Organização Mundial da Saúde. Prevenção do suicídio: um manual para profissionais de saúde em atenção primária. Genebra: OMS; 2000.

13. Vidal CE, Gontijo EC, Lima LA. Attempted suicide: prognostic factors and estimated excess mortality. Cad Saude Publica. 2013;29(1):175-87.

14. World Health Organization. Preventing suicide: a global imperative. Geneva: WHO; 2014.

15. Meleiro AMAS. Atendimento de pacientes com comportamento suicida na prática médica. Rev. bras. med. 2013;70:22-7.

16. Kotowski A, Roye C. Development of instructional competencies for assessing and managing suicide risk for baccalaureate nursing education: a modified Delphi study. Issues Ment Health Nurs. 2017;38(3):233-42.
17. Pereira AA, Costa ANd, Megale RF. Mental health for primary care family doctors: a contribution to improve educational programs. Rev Bras Educ Med. 2012;36(2):269-79.

18. Botega NJ, Reginato DG, Silva SV da, Cais CF, Rapeli CB, Mauro ML, et al. Nursing personnel attitudes towards suicide: the development of a measure scale. Braz J Psychiatry. 2005;27(4):315-8.

19. Magrini DF. Atitudes dos profissionais de enfermagem que atuam em emergências diante do comportamento suicida e fatores associados. Dissertação de Mestrado. Ribeirão Preto: Universidade de São Paulo; 2016.

20. Kamski L, Frank E, Wenzel V. Suicide in medical students: case series. Anaesthesist. 2012;61(11):984-8.

21. Kirchner LF, Queluz FNFR. Conhecimento e atitudes de universitários acerca do suicídio: influências sociodemográficas e acadêmicas. Brazilian Journal of Health Review. 2019;2(4):3120-30.

22. Magalhães CA, Neves DMM, Brito LMDM, Leite BBC, Pimenta MMF, Vidal CEL. Atitudes de estudantes de medicina em relação ao suicídio. Rev Bras Educ Med. 2014;38(4):470-6. doi: 10.1590/S010055022014000400008.

23. Silva LLT. Atitudes e percepções de estudantes e professores de enfermagem frente ao suicídio de adolescentes. Tese de Doutorado. Belo Horizonte: Universidade Federal de Minas Gerais; 2014.

\section{CONTRIBUIÇÃO DOS AUTORES}

Todos os autores colaboraram igualmente na elaboração, escrita e revisão do artigo.

\section{CONFLITO DE INTERESSES}

Os autores declaram não haver conflito de interesses neste estudo.

\section{ENDEREÇO PARA CORRESPONDÊNCIA}

Emerson Arcoverde Nunes. Hospital Universitário Onofre Lopes, Avenida Nilo Peçanha, 620, Natal, RN, Brasil. CEP: 59012-300.

E-mail: emerson_arcoverde@yahoo.com.br 